\title{
Data Driven Model Improved by Multi-Objective Optimisation for Prediction of Building Energy Loads
}

\author{
Saleh Seyedzadeha,b,*, Farzad Pour Rahimian ${ }^{\mathrm{c}, \mathrm{d}}$, Stephen Oliver ${ }^{\mathrm{a}, \mathrm{b}}$, Ivan \\ Glesk $^{\mathrm{a}}$, Bimal Kumar \\ ${ }^{a}$ Faculty of Engineering, University of Strathclyde, Glasgow G1 1XW, UK \\ ${ }^{b}$ arbnco, Glasgow, UK. \\ ${ }^{c}$ School of Computing, Engineering $\&$ Digital Technologies, Teesside University, Tees \\ Valley, Middlesbrough, UK \\ ${ }^{d}$ Department of Civil and Environmental Engineering (DICeA), Università degli Studi di \\ Firenze, Piazza di San Marco, 4, 50121 Firenze FI, Italy \\ ${ }^{e}$ Faculty of Engineering 86 Environment, Northumbria University, Newcastle, UK
}

\begin{abstract}
Machine learning (ML) has been recognised as a powerful method for modelling building energy consumption. The capability of ML to provide a fast and accurate prediction of energy loads makes it an ideal tool for decisionmaking tasks related to sustainable design and retrofit planning. However, the accuracy of these ML models is dependent on the selection of the right hyper-parameters for a specific building dataset. This paper proposes a method for optimising ML models for forecasting both heating and cooling loads. The technique employs multi-objective optimisation with evolutionary algorithms to search the space of possible parameters. The proposed approach not only tunes single model to precisely predict building energy loads but also accelerates the process of model optimisation. The study utilises simulated building energy data generated in EnergyPlus to validate the proposed method, and compares the outcomes with the regular ML tuning procedure (i.e. grid search). The optimised model provides a reliable tool for building designers and engineers to explore a large space of the available building materials and technologies.
\end{abstract}

Keywords: Building energy loads, Building energy prediction, Machine learning, Model optimisation, Energy performance

*Email: s.seyyedzadeh@gmail.com 


\section{Introduction}

There have been several approaches proposed to enhance the energy efficiency of buildings in many countries in recent decades. For instance in Europe, it was estimated in 2010 that 60 billion Euros could be saved annually by improving EU buildings' energy performance by 20 per cent [1].

Every attempt to optimise the energy performance of buildings involves a series of calculations to estimate the energy consumption and create an index, such as an 'energy performance indicator' or 'use intensity' from the measured data [2, 3]. Most prevailing optimisation methods are simulationbased where the energy-related objectives (i.e. energy consumption or gas emissions) are calculated by a Building Performance Simulation (BPS) tool such as EnergyPlus, TRNSYS and ESP-r. This approach restricts the computing complexity of the algorithms to BPSs' calculation time. As such, when a vast range of solutions are defined, the calculation and optimisation process may become extremely costly and cumbersome. For this reason, most of the studies which focused on decision making for energy performance improvement of buildings either investigated basic and simple optimisation models or targeted retrofitting only one or two parts of envelopes to pare-down total calculation time and cost. It should also be noted that the majority of studies targeted residential buildings, and there are only a few examples of research related to tertiary buildings. A key component of achieving global development and meeting climate change mitigation targets is the optimisation of the entire building stock. This process requires significant testing and planning to deliver.

With the tremendous growth in the amount of valid and attainable datasets of buildings and collection of Big Data from smart buildings, there is an increasing interest in the employment of Artificial Intelligent (AI) methods specifically Machine Learning (ML) techniques for analysing, modelling, and predicting building data [4, 5].

The precision and suitability of the data and the relationships inferred from it become a critical fact in the successful application of ML models. As ML methods build s model over a historical dataset, the main and most important step for having accurate predictions is the extraction of relevant features. Depending on the nature of predictions (the energy indicator and forecasting period), this variable could include simple basic weather indices 
(e.g. temperature and humidity) or complex building characteristics and climate parameters. Previous research has demonstrated that rather than feature extraction the process of tuning a model itself not only increases the predictive accuracy but also reduces model complexity, ease of use, and consistency of predictions [6]. It has been argued that considering occupancy in retrofit decision-making, particularly in populated real estate properties such as higher education buildings, could leverage energy efficiency [7].

ML techniques have been widely used for modelling building energy loads and performance. Traditionally, the default values for hyper-parameters have been used in this field. However, in recent years researchers have started to tune the ML models to have more accurate predictions of energy metrics [8, 9, 10, 11]. Tuning ML model hyper-parameters using a grid search can be time-consuming when a complex method is chosen such as Artificial Neural Networks (ANN) or models based on decision trees.

When MLs are utilised for forecasting multiple measures such as heating and cooling loads, models need to be optimised for both the targets [12, 13]. This procedure, in turn, increases the time required for processing and improves the usability of MLs.

In the proposed method, evolutionary-based multi-objective optimisation (MOO) algorithm was employed to smartly explore the ML model's configuration parameters space and suggest a set of packages for maximising ML accuracy for both heating and cooling load predictions. This study applied a Random-Forest (RF) model because a python implementation is capable of providing the multivariate forecasting.

Section 2 provides an overview of the preceding studies with regards to tuning ML models with the purpose of building energy indicators forecasting. Afterwards, the RF method and the studied dataset are described in Section 3. Section 4 presents the results of the proposed ML optimisation approach. The final section provides detailed discussions and recommendations for future work.

\section{Background and Motivations}

Machine learning algorithms are categorised into two groups: supervised learning, in which the data is labelled, and unsupervised learning, where there is no target for the records in the dataset. Supervised learning is a regression analysis or a set of classifications linking inputs factors $(X)$ to single or multiple "output" variables $(Y)$. Whereas, in unsupervised learning, data is 
organised into clusters by pulling out similarities between various samples within the dataset. As such, unsupervised learning is applied to unlabelled datasets. In contrast, in the supervised learning algorithms, the input-output relationships are detected and used for the prediction of new records.

Kalogirou et al. 14] were the first team of researchers who employed ML models to determine the heating loads of a building, taking into consideration the building envelope features as well as the temperature outside. In a related study, ANNs were used in estimating the electricity demand level in a holiday residence, simulated in ZID software [15]. A more recent study [16] also applied ANNs to forecast the heating loads of a simulated house in Nicosia, Cyprus with the aim of finding a Pareto scenario when dealing with various types of walls and roofs, with different constructional arrangements and material types. They utilised TRaNsient SYstem (TRNSYS) as the energy evaluation engine for all building combinations. The model was then validated by comparing the calculated energy consumption with the actual measurement from the building. More recent studies have widely used ANN for estimating building heating and cooling loads [17, 18, 19, 20], electricity demand [21, 22, 23], and energy consumption [24, 25, 26].

Yalcintas [27, 28] created an ANN model for estimating energy benchmarking considering tropical climate weather data and including chiller data. These buildings included offices, classrooms, laboratory-type buildings, and miscellaneous use buildings. The efficiency of 'energy use intensity calculation' is examined against multiple linear regression techniques indicating an exceptional improvement over it. Hong [29] also used ANN for energy performance evaluation of primary and secondary schools established in the UK by computing electrical and heating usage. Although it was found that the accuracy of ANN outperforms traditional statistical models, these predictions were not as accurate as simulation and engineering calculations [30]. Wong et al. [31] applied ANN on a commercial building, including day-lighting located in Hong Kong to assess the dynamic energy performance. EnergyPlus and methods for computation of interior reflection are utilised to produce the building daily energy load. Nash-Sutcliffe Efficiency Coefficient is used as the primary measurement to investigate ANN accuracy in predicting cooling, heating, electric lighting and total electricity consumption. Ascione et al. 32 trained ANN models to predict the energy performance of existing and renovated buildings, along with the occupant thermal comfort.

Support Vector Machine (SVM) for prediction of building energy indicators was introduced by Dong et al. 33] and adopted by a number of studies 
for estimation of cooling and heating loads [34, 35, 36, 37, electricity consumption [11, 38], and energy consumption [39, 40, 41, 9, 42, 43].

The use of ensemble ML models (e.g. RF and gradient boosted regression trees) in the building energy domain is restricted to recent years [44, 45, 46, 47, 6], despite an established track-record of utilisation in other disciplines. Li et al. 48, compared SVM, ANN and ensemble models on prediction of building energy performance by using trust metric to evaluate the reliability of the models. The superiority of SVM and ML over the ensemble and linear models was concluded. However, the authors did not optimise the models to generate the Pareto frontier. In a recent study [6] which tuned and compared the most commonly used models revealed the better performance of ensemble models over others. Papadopoulos et al. [12 also compared different ensemble models in estimation of the energy performance of residential buildings (including 768 variations of a model building) evaluated using Ecotect software.

Table 11 outlines ML application on the prediction of building energy usage. 
Table 1: ML modelling for prediction of building energy loads and performance.

\begin{tabular}{|c|c|c|c|c|}
\hline ML & Term & Building & Features & Ref \\
\hline ANN & Month & $\begin{array}{l}\text { schools in } \\
\text { England } \\
\text { and Wales }\end{array}$ & $\begin{array}{l}\text { Construction year, Phase of education, } \\
\text { No. of pupils, Internal conditioning, } \\
\text { Orientation, Facade adjacency, Floor } \\
\text { area, Depth ratio, Compactness ratio, } \\
\text { Glazing ratio \& type, Roof shape \& } \\
\text { glazing, Heating \& Cooling degree-days }\end{array}$ & 29 \\
\hline ANN & & $\begin{array}{l}\text { Educa- } \\
\text { tional } \\
\text { building }\end{array}$ & $\begin{array}{l}\text { Operation hours, Age, Square feet area, } \\
\text { Yearly electricity usage, Percentage } \\
\text { electricity used for lighting, air } \\
\text { conditioning, plug loads }\end{array}$ & 28 \\
\hline ANN & Year & $\begin{array}{l}\text { Office } \\
\text { buildings }\end{array}$ & $\begin{array}{l}\text { geometry }(9) \text {, envelope }(30) \text {, operation } \\
(6) \text { and HVAC (3) }\end{array}$ & 32 \\
\hline ANN & Year & $\begin{array}{l}\text { Schools in } \\
\text { UK }\end{array}$ & $\begin{array}{l}\text { Glazing ratio, Glazing type, Roof } \\
\text { shape, Roof glazing, Heating degree } \\
\text { days, Cooling degree days }\end{array}$ & 18 \\
\hline ANN & & $\begin{array}{l}\text { Residential } \\
\text { buildings }\end{array}$ & $\begin{array}{l}\text { Degree days, Net volume \& floor area, } \\
\text { Dispersant surface, Opaque to glazed } \\
\text { ratio, Construction year \& period, } \\
\text { Thermal conductivity, Average floor } \\
\text { height, Opaque \& glazed surface area, } \\
\text { Non-linear features }\end{array}$ & 49 \\
\hline ANN & Day & $\begin{array}{l}\text { Reference } \\
\text { office } \\
\text { building }\end{array}$ & $\begin{array}{l}\text { External weather conditions, Building } \\
\text { envelope designs, Day type }\end{array}$ & 31 \\
\hline ANN & Hour & $\begin{array}{l}\text { Simulation } \\
\text { models }\end{array}$ & $\begin{array}{l}\text { Solar radiation, Wind speed, Outside } \\
\text { temperature \& mass flow rate of hot } \\
\text { water of previous } 24 \mathrm{~h}, \text { Hot water } \\
\text { temperature }\end{array}$ & 50 \\
\hline
\end{tabular}


ML modelling for prediction of building energy loads and performance (cont.)

\begin{tabular}{|c|c|c|}
\hline SVM Day & $\begin{array}{l}\text { Single- } \\
\text { story } \\
\text { mass-built } \\
\text { buildings }\end{array}$ & $\begin{array}{l}\text { Dry bulb and relative humidity, Wind } \\
\text { speed, Direct solar, Ground } \\
\text { temperature, Outdoor air density, } \\
\text { Water mains temperature, No. of } \\
\text { occupants, Heat gain of lights, electric } \\
\text { equipment and window, Heat loss for } \\
\text { walls, Infiltration volume, Heating } \\
\text { outlet temp }\end{array}$ \\
\hline $\begin{array}{l}\text { SVM, Year } \\
\text { ANN }\end{array}$ & $\begin{array}{l}59 \\
\text { residential } \\
\text { buildings } \\
\text { in China }\end{array}$ & $\begin{array}{l}\text { Mean heat transfer coefficient of } \\
\text { building walls, Mean thermal inert } \\
\text { index of walls, Roof heat transfer } \\
\text { coefficient, Building size coefficient, } \\
\text { Absorption coefficient for solar } \\
\text { radiation of exterior walls, Window to } \\
\text { wall ratio, Shading coefficient of } \\
\text { window, Integrated shading coefficient }\end{array}$ \\
\hline ANN Hour & $\begin{array}{l}\text { An institu- } \\
\text { tional } \\
\text { facility }\end{array}$ & $\begin{array}{l}\text { Outside temperature and relative } \\
\text { humidity, Boiler outlet water } \\
\text { temperature and flow-rate, Chiller } \\
\text { outlet water temperature and flow-rate, } \\
\text { Supply air temperatures for hot, cold } \\
\text { duct, Supply and return control } \\
\text { settings, Indoor temperatures of } \\
\text { different zones }\end{array}$ \\
\hline $\begin{array}{l}\text { RF, } \\
\text { GBRT Year }\end{array}$ & $\begin{array}{l}\text { Model } \\
\text { building }\end{array}$ & $\begin{array}{l}\text { Relative compactness, Surface area, } \\
\text { Wall area, Roof area, Overall height, } \\
\text { Orientation, Glazing area, Glazing area } \\
\text { distribution }\end{array}$ \\
\hline
\end{tabular}

\subsection{Research Gap}

Recently, researchers working in modelling building energy have identified the potential of ML model [52, 53, 54, 8, 12. The main role of extracting logically appropriate feature of building physics, conditions and environments in the accuracy of surrogates models is clear. However, without tuning the ML models, it is not possible to get the real benefit from them. 
Simple models with few parameters like SVM are easy to optimise, but when the number of hyper-parameters is increased the search space grows exponentially. For example, to tune an RF with six parameters, a grid search will explore more than four thousands possible configurations. That is why traditionally, the researchers mostly relied on default values for those hyperparameters. However, such models provide far more accurate results by precisely tuning in comparison with SVM or Gaussian process regression [6].

Forecasting two or more building energy measures such as heating and cooling loads simultaneously requires even more expertise and investigation. The use of complex model and grid search for such applications is not a viable solution, due to the complexity in processing time as well as the selection of the ideal model.

This study outlines a detailed method to train one single model for prediction of both heating and cooling loads of buildings and maximise the ML model's efficiency. Though the demonstration presented here are from simulated data, the approach is also applicable to measured energy data.

\section{Methodology}

ML models work as black boxes, meaning that the detailed relations of energy performance and building characteristics and weather data are not provided. As mentioned earlier, the initial phase of data-driven modelling is the extraction of a feature set for representing the energy system. Surrogate methods model a system with fewer features than engineering approaches. However, formulating a logical set of variables for these models is both essential and laborious, particularly when modelling complex systems such as the energy efficiency of commercial buildings. The determined features might be building characteristics or weather data or complex parameters computed from primary ones, for example, median dew point temperature [5]. After feature engineering, which also includes imputation/elimination of missing data and normalisation, the next step is to optimise the model itself. In this phase, the hyper-parameters of ML models are tuned in a way to achieve the highest possible accuracy. There are no explicit rules to guide the selection of these parameters by considering the dataset detail such as the number of records or input variables. Hence, the best dataset can be selected using a brute-force search. Another way to find the best feature is to use evolutionary algorithms such as a genetic algorithm. This not only reduces the processing time of the search procedure but also provides better performance. 
In traditional Grid-search method, a specified set of possible values for each parameter is required. However, evolutionary algorithms are able to select the values from a determined continuous space or a discrete set.

In the proposed method, a MOO technique is utilised to exploit genetic algorithm in the optimisation of ML models for prediction of heating and cooling loads of buildings. Figure 1 demonstrates the proposed optimisation procedure for selecting the best hyper-parameters. Here, the ML parameters are defined as the MOO variables to generate several sets with which ML model accuracy is maximised for forecasting both energy loads. Most implementations of the established ML models such as NN and RF support the concurrent prediction of multiple targets. However, choosing a set of hyper-parameters might improve the prediction accuracy of one target but less the accuracy of the other objective function [6].

First, MOO is initiated with pre-set values (in this study, we used default values suggested by the Python library) to create a model. This is evaluated using a 10-fold cross validation method. In this approach, the dataset is divided into 10 equal segments. Then a model is trained using 9 parts and tested on the remaining one, and this procedure is repeated until the accuracy of the model is assessed covering all parts. Finally, the average values of the model performance (e.g. mean absolute error) of all 10 folds is sent to the MOO. It continues generating new samples and evaluating models until it reaches 500 iterations.

In the following section, the dataset, $\mathrm{RF}$ model and the utilised MOO methods are elaborated.

\subsection{Dataset}

In this study, a dataset including residential and commercial building models whose energy loads are calculated using EnergyPlus software is utilised. The data comprises 460,000 records characterised by seven structural, sixteen climate and three mixed features as presented in Table 2. The buildings' attributes were adopted from models obtained from US DOE commercial building reference databases and residential houses in Geneva, Switzerland and north of Germany. To enrich the dataset, the variation of those models are simulated in various climate conditions collected from meteorological data of metropolitan areas from all around the world and a generated synthetic weather data [55]. For detail of the features refer to Table 3 presented in $[6]$ 


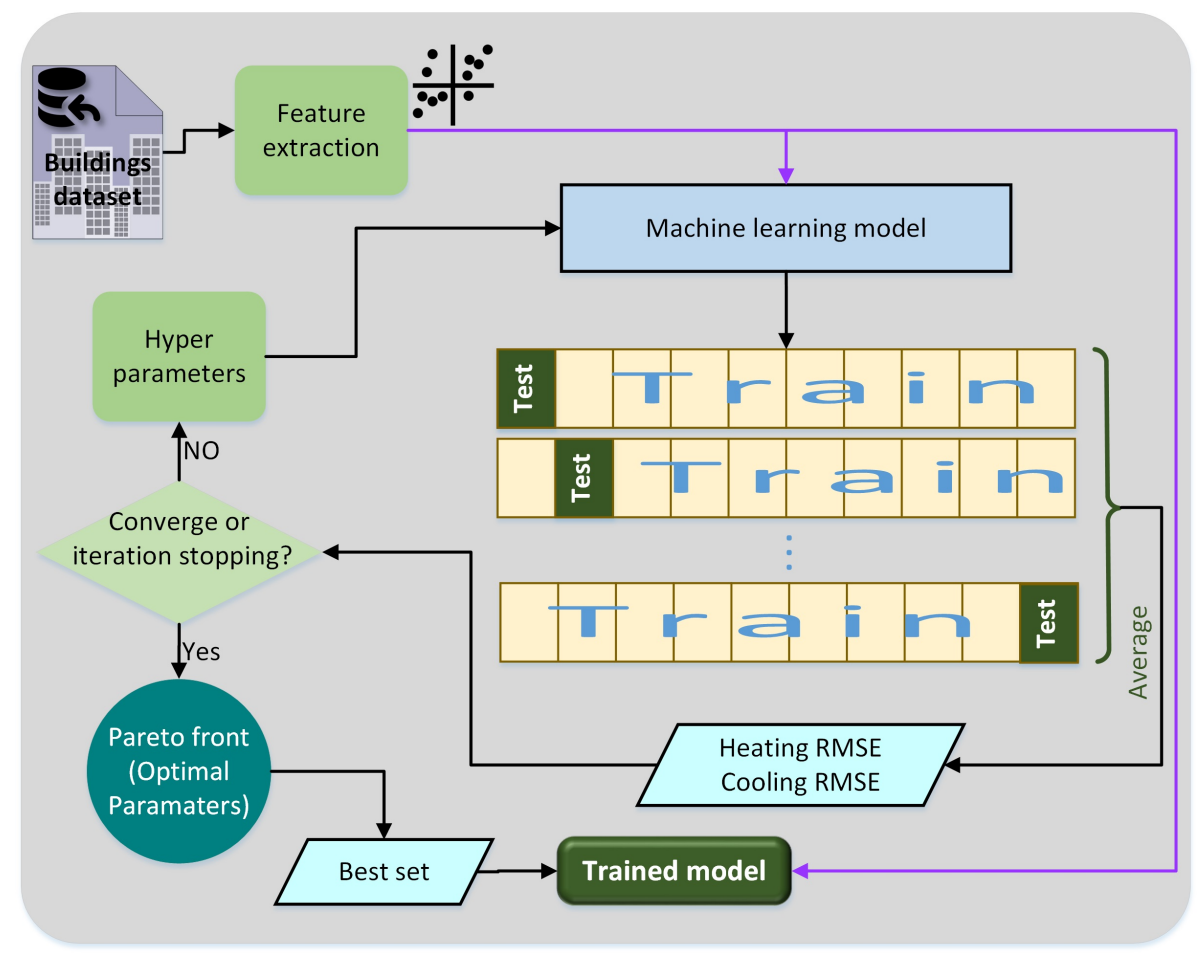

Figure 1: Schematic diagram of the proposed ML optimisation method.

Figure 2 illustrates the frequency plot of the selected features from the EnergyPlus simulated dataset. It can be noted that almost all variables are somewhat spread over the feasible predetermined values. The correlation heat-map matrix provided in Figure 3 presents the independency of different features from each other particularly the ones associated with building physics.

\section{2. $R F$}

$\mathrm{RF}$ is an ensemble of randomised decision trees (DTs). A DT encompasses the establishment of an ML model in a tree structure form by a nonparametric algorithm. DT progressively divides the given data into elemental subsets until reaching a single sample residing in each sub-group. The inner and outer sets are called nodes and leaf nodes. The accuracy of DT is significantly dependent on the samples' distribution in the learning dataset. As such, DT is always introduced as an unsteady method, where even minor 

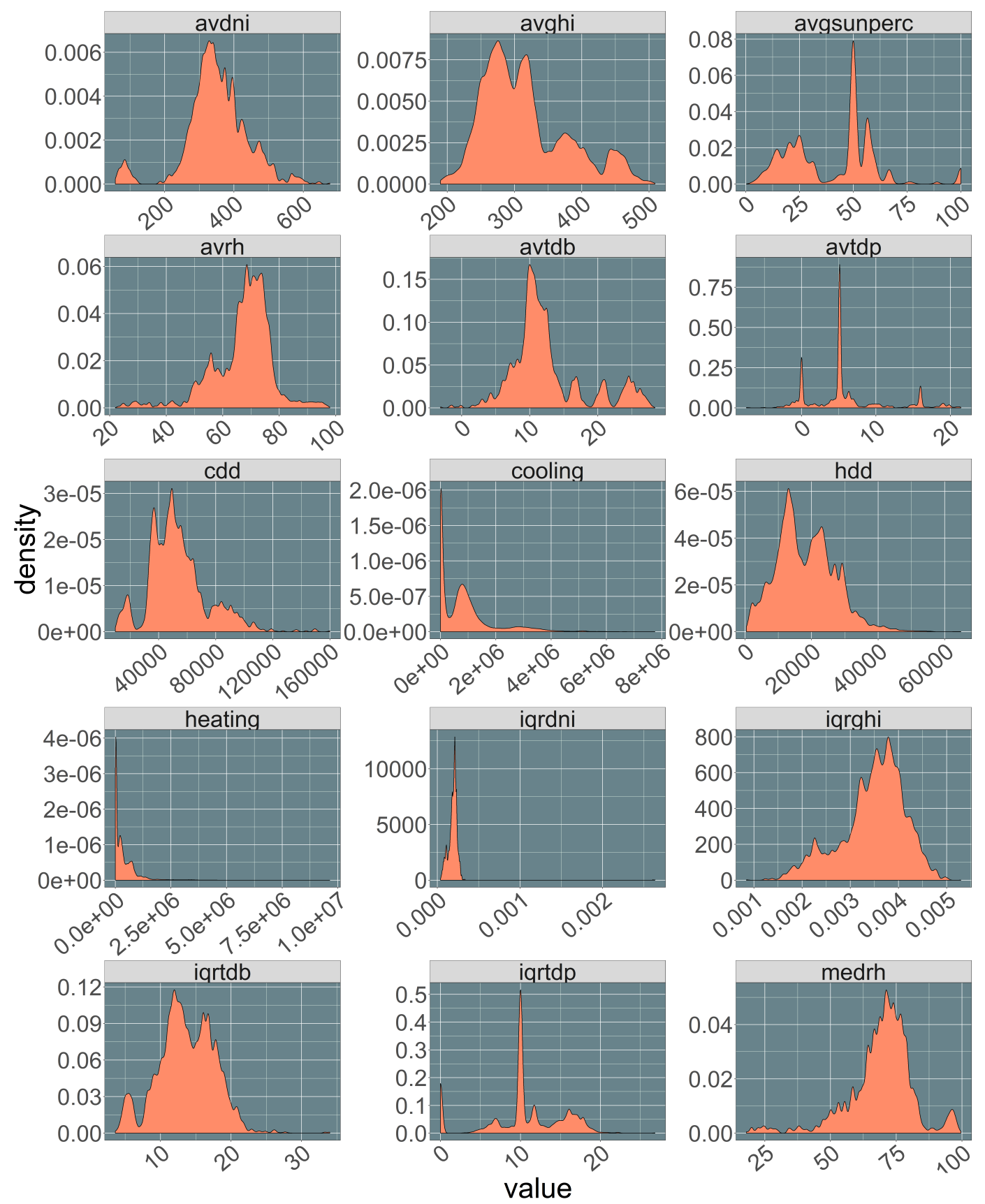

Figure 2: Distribution of the selected features for building energy data. 

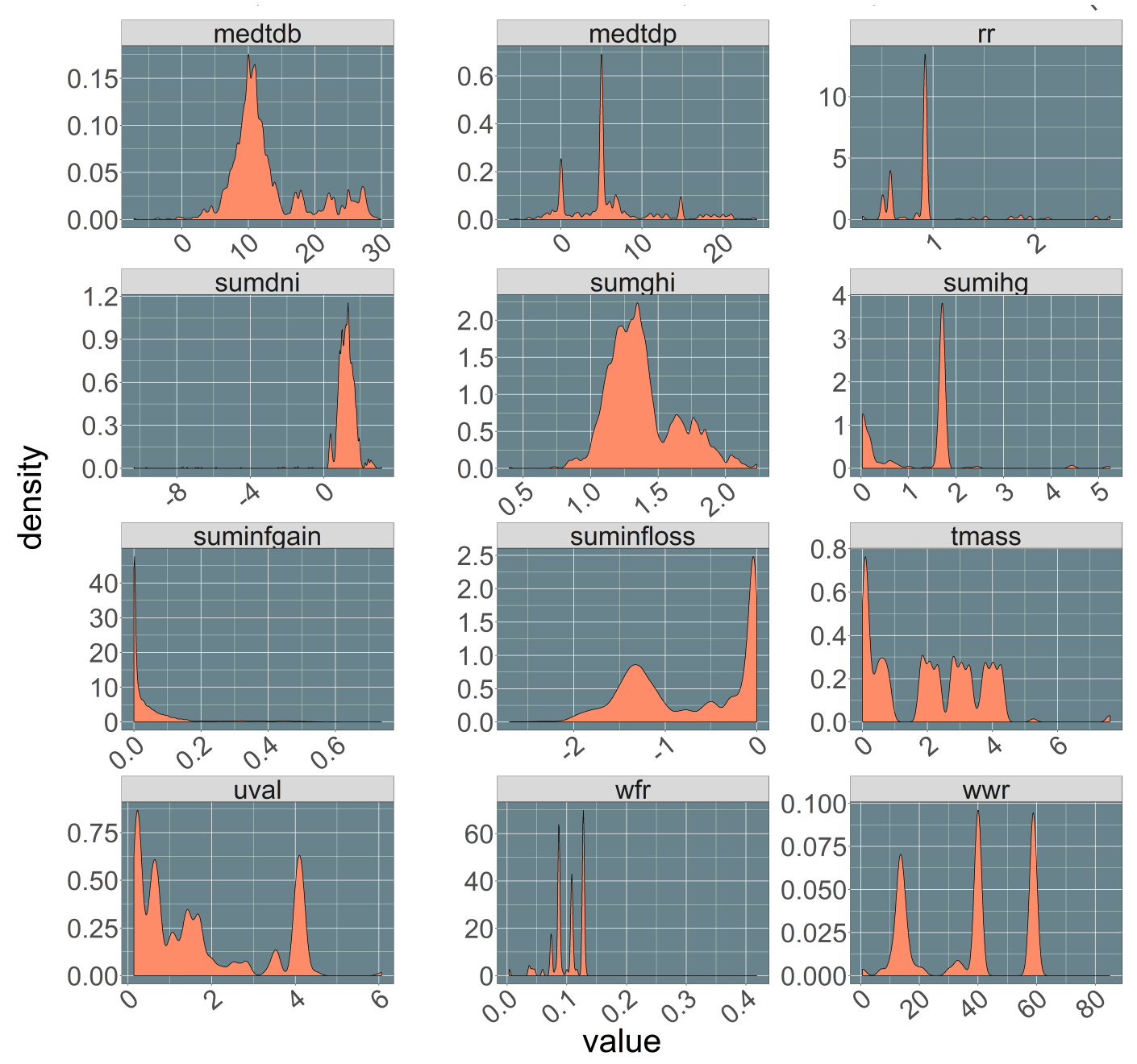

Figure 2 (Cont.): Distribution of the selected features for building energy data. 


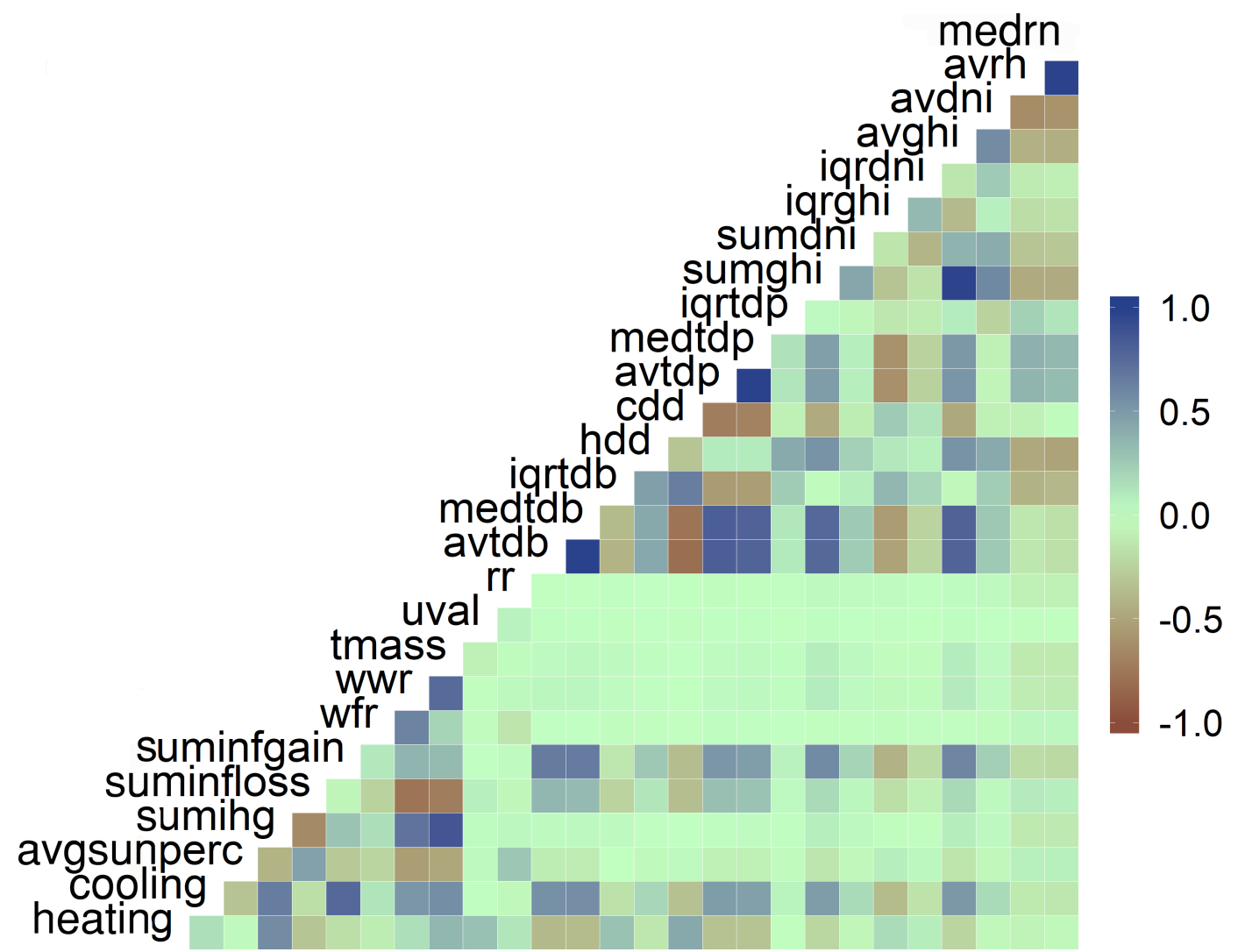

Figure 3: EnergyPlus data features correlation map. 
Table 2: List of EnrgyPlus features extracted for model training

\begin{tabular}{|c|c|c|c|}
\hline Feature & Code & Feature & Code \\
\hline $\begin{array}{l}\text { Average U-value of } \\
\text { envelope }\end{array}$ & uval & $\begin{array}{l}\text { Sum of thermal storage } \\
\text { capacity }\end{array}$ & tmass \\
\hline $\begin{array}{l}\text { Ratio of window area to } \\
\text { wall area }\end{array}$ & $W W R$ & $\begin{array}{l}\text { Ratio of window area to } \\
\text { floor area }\end{array}$ & $W F R$ \\
\hline $\begin{array}{l}\text { Form Factor (Volume / } \\
\text { Wall Area) }\end{array}$ & $f f$ & Median relative humidity & medrh \\
\hline $\begin{array}{l}\text { Roof Ratio (Roof / Wall } \\
\text { Area) }\end{array}$ & $r r$ & $\begin{array}{l}\text { Average sunlit percentage } \\
\text { of envelope }\end{array}$ & avgsunperc \\
\hline $\begin{array}{l}\text { Annual sum of energy } \\
\text { gained due to infiltration }\end{array}$ & suminfgain & $\begin{array}{l}\text { Annual sum of energy lost } \\
\text { due to infiltration }\end{array}$ & suminfloss \\
\hline $\begin{array}{l}\text { Annual sum of Internal } \\
\text { Heat Gain }\end{array}$ & sumI HG & $\begin{array}{l}\text { Annual sum of cooling } \\
\text { degree days }\end{array}$ & $c d d$ \\
\hline $\begin{array}{l}\text { Annual sum of heating } \\
\text { degree days }\end{array}$ & $h d d$ & $\begin{array}{l}\text { Annual average of dry bulb } \\
\text { temperature }\end{array}$ & avgtdb \\
\hline $\begin{array}{l}\text { Median dry bulb } \\
\text { temperature }\end{array}$ & medtdb & $\begin{array}{l}\text { Inter-quartile range of dry } \\
\text { bulb temperature }\end{array}$ & iqrtdb \\
\hline $\begin{array}{l}\text { Annual average of dry } \\
\text { point temperature }\end{array}$ & $a v g t d b$ & $\begin{array}{l}\text { Median dew point } \\
\text { temperature }\end{array}$ & $m e d t d b$ \\
\hline $\begin{array}{l}\text { Inter-quartile range of dew } \\
\text { point temperature }\end{array}$ & $i q r t d b$ & $\begin{array}{l}\text { Annual average of global } \\
\text { horizontal irradiation }\end{array}$ & avgghi \\
\hline $\begin{array}{l}\text { Annual sum of global } \\
\text { horizontal irradiation }\end{array}$ & sumdni & $\begin{array}{l}\text { Inter-quartile range of } \\
\text { global horizontal } \\
\text { irradiation }\end{array}$ & $i q r d n i$ \\
\hline $\begin{array}{l}\text { Annual average of direct } \\
\text { normal irradiation }\end{array}$ & avgghi & $\begin{array}{l}\text { Annual sum of direct } \\
\text { normal irradiation }\end{array}$ & sumdni \\
\hline $\begin{array}{l}\text { Inter-quartile range of } \\
\text { direct normal irradiation }\end{array}$ & $i q r d n i$ & $\begin{array}{l}\text { Annual average of relative } \\
\text { humidity }\end{array}$ & avgrh \\
\hline
\end{tabular}

alteration in the input data can change the whole structure. A set of DTs are often employed in conjunction with each other, and calculated average representative estimated values, in order to address the aforementioned issue. In other words, bagging and optionally bootstrapping are applied in RF with the aim of combining the separate models containing a similar set of 


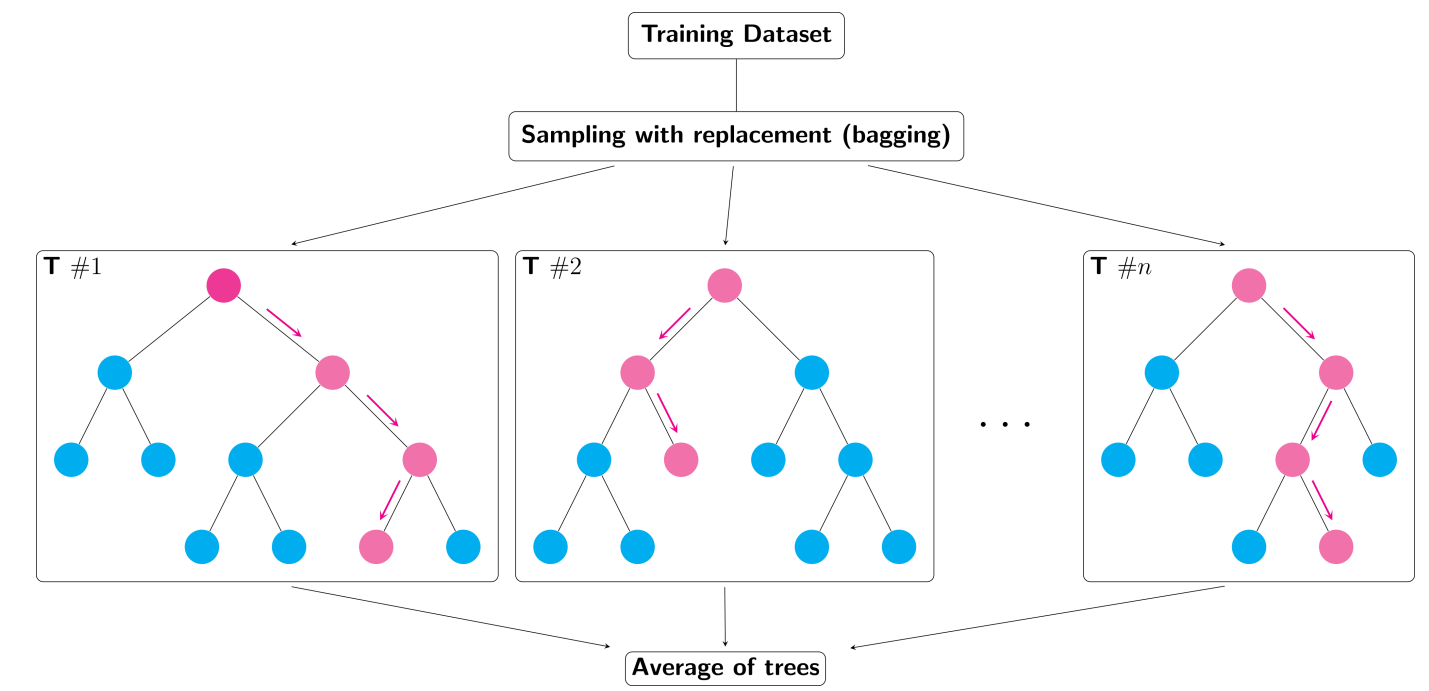

information and generating a linear combination from various independent trees. The RF training procedure mechanism is illustrated in Figure 4

Figure 4: Diagram of an RF model with $n$ independent trees.

Determining several hyper-parameters is a prerequisite to adopting RF. The first parameter to determine here is the number of independent trees of the forest. The precision of the model and training is always negatively related to predicting computational complexity; therefore, an optimal model is achieved through balancing these together. There are also other settings to be considered. This includes the number of variables while seeking the best split, whether or not apply bootstrapping while creating independent trees, and a minimum number of a data sample to split on nodes.

\section{3. $\mathrm{MOO}$}

There are several tuning methods for optimising the MLs for accurate predictions. These approaches include grid and random search techniques, evolutionary algorithms or Bayesian optimisation. Generally, these methods are applied to optimise a single objective criterion. However, in applications where two or more objective functions (i.e. heating and cooling loads) are optimised, those approaches are not adequate to designate the behaviour of the ML, and the Pareto front of multiple criteria has to be considered. Usually, for each objective, an ML is independently tuned to get the best 
hyper-parameters, and the most accurate model and its configuration are selected eventually. The main disadvantage of this strategy is the high timecomplexity of tuning the separate models. We propose a MOO method for automated hyper-parameter selection in modelling the heating and cooling loads of a building. The proposed method reduces the time required for tuning, speeds up the model predictions and decreases human effort for implementing ML. The general MOO problem is presented mathematically as: Minimise:

$$
F(\hat{x})=\left[f_{1}(\hat{x}), f_{2}(\hat{x}), \cdots, f_{m}(\hat{x})\right]^{T}
$$

Subject to:

$$
\begin{aligned}
& g(\hat{x}) \leq 0 \\
& h(\hat{x})=0
\end{aligned}
$$

where

$$
\begin{gathered}
x_{i}^{\text {min }} \leq x_{i} \leq x_{i}^{\max }(i=1,2, \cdots, n) \\
x=\left[x_{1}, x_{2}, \cdots, x_{n}\right]^{T} \in \Theta \\
y=\left[y_{1}, y_{2}, \cdots, y_{n}\right]^{T} \in \Psi
\end{gathered}
$$

Here $m$ is the number of objective functions which is three in this case. $\Theta$ is the search space with $n$ dimensions and identified by upper and lower bounds of decision variables $x_{i}(i=1,2, \cdots, n)$.

$$
\begin{aligned}
x^{\max } & =\left[x_{1}^{\max }, x_{2}^{\max }, \cdots, x_{n}^{\max }\right]^{T} \\
x^{\text {min }} & =\left[x_{1}^{\text {min }}, x_{2}^{\text {min }}, \cdots, x_{n}^{\text {min }}\right]^{T}
\end{aligned}
$$

$\Psi$ is an $m$-dimensional vector space of objective functions and defined by $\Theta$ and the objective function $f(x) \cdot g_{j}(\vec{x}) \leq 0(j=1,2, \cdots, p)$ and $h(\vec{x})=$ $0(j=1,2, \cdots, q)$ denotes $p$ and $q$ which are respectively the number of inequality and equality constraints. If both $p$ and $q$ are equal to zero, then the problem is simplified as an unconstrained optimization problem.

Figure 5 shows a hypothetical Pareto frontier for the optimisation of two objective functions which are energy loads estimation errors. These solutions (set of ML hyper-parameters) have been enclosed by a vector of an ideal 
solution and a vector of dominated results, delimiting the upper and the lower borders of optimal packages. An ideal or utopia point is a theoretical notion relative to an ideal target in which each objective is optimised without paying attention to the satisfaction of the others. MOO tries to produce solutions as close to the Pareto optimal front with a possible uniform distribution. When the non-dominated solutions are recognised, decision-makers choose one as a final answer in accordance with the problem and individual preferences.

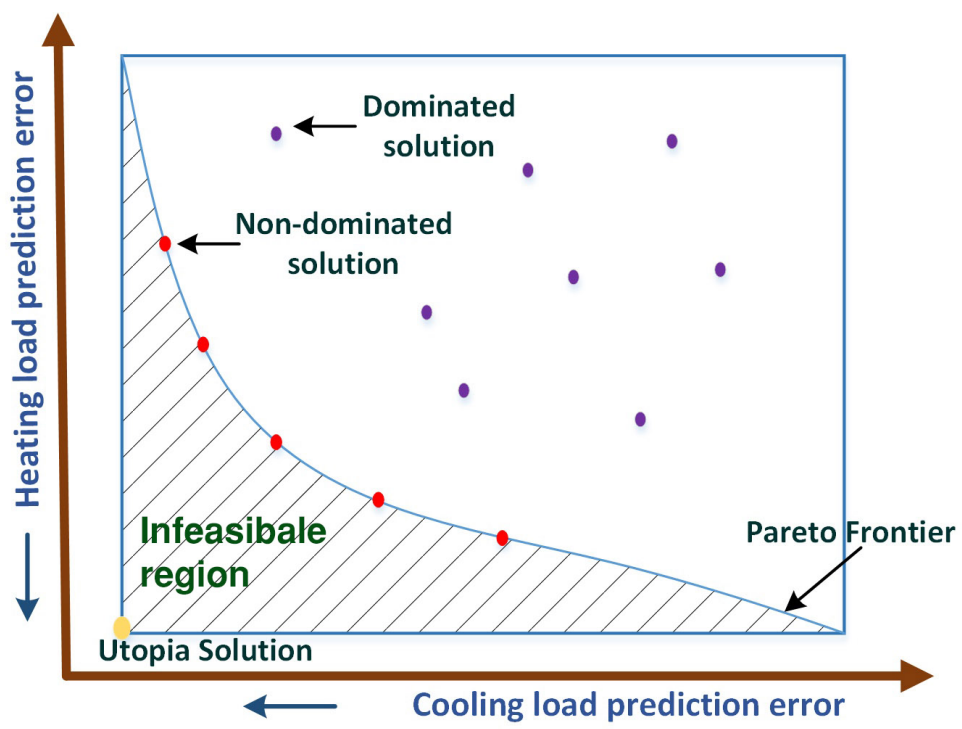

Figure 5: An example Pareto frontier of minimising errors in heating and cooling loads predictions.

Our tuning method involves an improved multi-objective genetic algorithm (NSGA-II) [56]. Genetic algorithm is initiated by randomly generated solutions as a population and sorts them into fronts based on non-domination criteria. These solutions are evolved from one generation to another based on the objective evaluation, selection, crossover and mutation operators.

\subsection{Evaluation criteria and optimisation variables}

As mentioned earlier, the objective functions for the optimisation problem determine the accuracy of a model in the prediction of heating and cooling loads. Each model is evaluated using k-fold cross-validation in which the accuracy of each fold is calculated as root mean square error (RMSE) of the 
prediction test set. The average RMSE value of heating and cooling loads in all folds is computed and regarded as the final value for the objective functions.

When the MOO algorithm generates a population, each solution contains a set of RF parameters. Table 3 summarises these variables.

Table 3: List of RF parameters which are considered as MOO variables

\begin{tabular}{|c|c|c|c|}
\hline Parameter & Description & Туре & Values \\
\hline$n_{-}$estimator & $\begin{array}{l}\text { Count of independent trees in the } \\
\text { formation of the forest }\end{array}$ & Integer & $\begin{array}{l}200- \\
1200\end{array}$ \\
\hline max_features & $\begin{array}{l}\text { Count of input variables in } \\
\text { creating each independent tree }\end{array}$ & $\mathrm{Cat}$ & 26,5 \\
\hline max_depth & depth of the tree & Int & 100 \\
\hline $\begin{array}{l}\text { min_samples } \\
\text { split }\end{array}$ & $\begin{array}{l}\text { The minimum samples in splitting } \\
\text { an internal node }\end{array}$ & Integer & $2-10$ \\
\hline $\begin{array}{l}\text { min_samples } \\
\text { leaf }\end{array}$ & $\begin{array}{l}\text { The minimum number of samples } \\
\text { required to be at a leaf node }\end{array}$ & Integer & $1-10$ \\
\hline bootstrap & $\begin{array}{l}\text { Whether or not to apply } \\
\text { bootstrapping samples while } \\
\text { generating the trees }\end{array}$ & Boolean & $\begin{array}{l}\text { True, } \\
\text { False }\end{array}$ \\
\hline
\end{tabular}

\section{Results}

This study used Python programming language and packages for implementing the proposed algorithms. The study used a PC with Intel Core i7-6700 3.4GHz CPU, 32GB RAM ( with no utilisation of GPU processing) for running the experiments.

Using conventional Grid search method requires further investigation to decide the topmost hyper-parameters for the ML model. Besides, the existing solutions are not developed to calculate the accuracy of predicting multiple targets. Hence, a custom function is needed to perform the task. The proposed method generates non-dominating solutions in which models accuracy in estimating heating and cooling loads are the highest. Furthermore, in a Grid search, it is not possible to search every potential value for the parameters in the grid due to the size of the vast search space. Therefore, 
n_estimators

bootstrap max_depth max_features min_samples_split min_samples_leaf

as the hyper-parameters are discretely introduced to the grid, the chance of success of the optimisation algorithm, which smartly selects the values from predefined intervals is higher to build a model with more reliable accuracy.

Figure 6 demonstrates the top 5 solutions, the ML parameters and models accuracies for heating and cooling loads in terms of RMSE. Among those, the two closest solutions to the utopian point are $S 4$ and $S 5$. The number of trees in $S 4$ is lower than $S 5$ resulting in faster training and predictions. As such, $S 4$ is suggested as the final set of parameters for modelling energy loads of the selected building dataset.

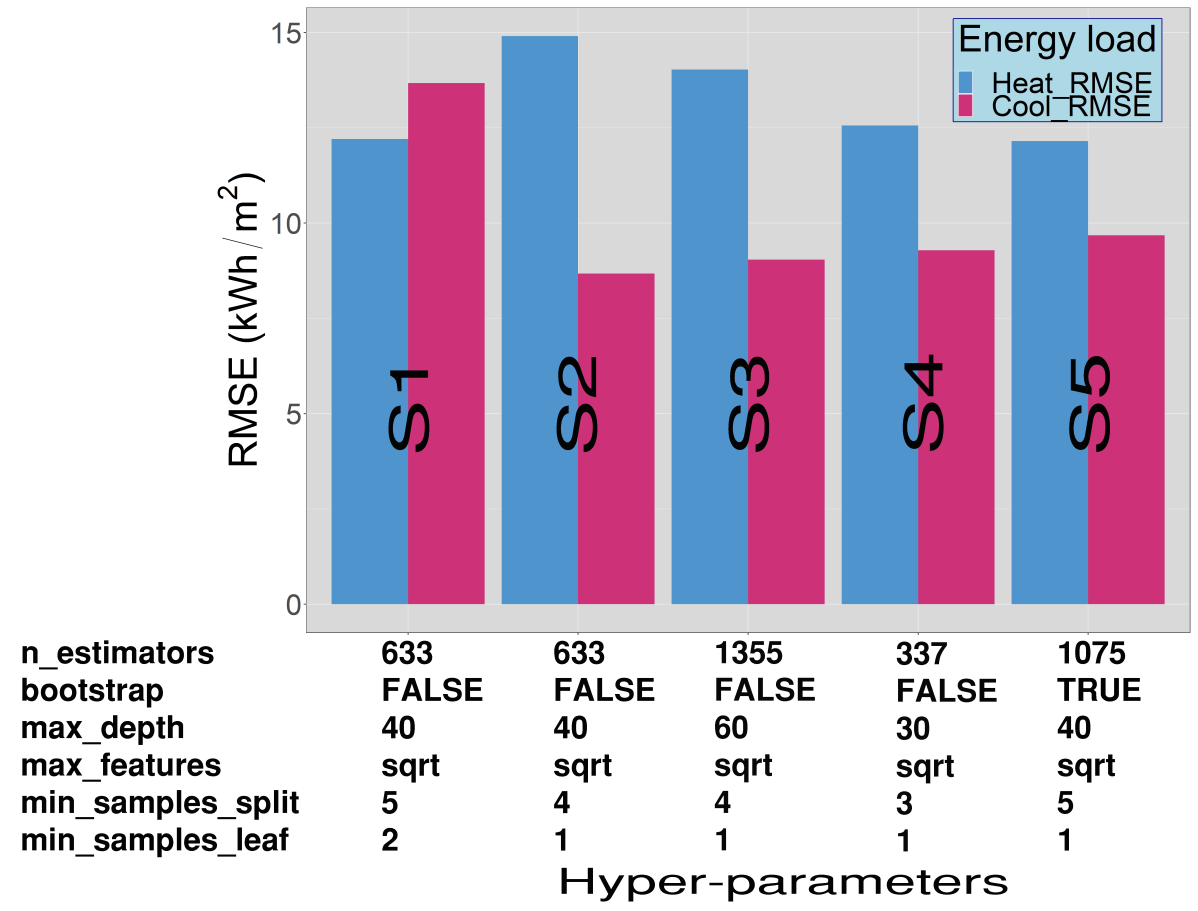

Figure 6: Top solutions provided by MOO for predicting heating and cooling loads of buildings.

Performance of the selected model tested using the 10-fold cross-validation over 5,000 randomly selected samples along with the results from Grid search, and the original study is summarised in Table 4. It can be seen that the selection of the right ML model and optimising the parameters using a Grid search method, the accuracy of predicting energy loads is considerably increased. The proposed MOO approach not only reduces the tuning time but 
also improves the performance of the models by precise tuning. The selection of 1,500 as the number of evolutionary algorithm iterations was based on a rule of thumb while the best model was identified at the 879th iteration.

Table 4: Results comparison of the proposed method, Grid search and the original study

\begin{tabular}{|c|c|c|c|c|}
\hline \multicolumn{3}{|c|}{ Best RMSE } & \multicolumn{2}{|l|}{ Complexity } \\
\hline Method & Heating & Cooling & No. of Iterations & Tuning time (h) \\
\hline Moo & 12.72 & 9.4 & 7,000 & 349 \\
\hline Grid Search $\overline{[6]}$ & $\overline{1} \overline{2} . \overline{5} \overline{6}$ & $\overline{9} . \overline{2} 8$ & $\overline{1}, \overline{50} \overline{0}$ & $\overline{79} \overline{9}^{-}$ \\
\hline Orginal Study [57] & $\overline{2} \overline{5} . \overline{0} \overline{5}$ & $\overline{12.84}$ & $\begin{array}{l}\overline{\text { Using }} 4,000 \text { ran } \\
\text { Gaussian Process }\end{array}$ & $\begin{array}{l}\text { om samples and } \\
\text { Regression }\end{array}$ \\
\hline
\end{tabular}

To illustrate the effect of data size on the accuracy of supervised models, RMSE is plotted versus the number of training and test records forecasting heating and cooling loads of EnergyPlus data which is depicted in Figure 7. To evaluate the accuracy and generalisation of RF model in predicting energy loads, 10-fold cross-validation is utilised. The prediction confidence intervals, which are maximum and minimum values of all folds along with the mean value, are illustrated in Figure 7. Figure 8 shows the average training and testing times versus the number of records.

From two figures, it can be seen that there is a trade-off between accuracy and time complexity of the model. However, the results indicate that the sample size of 45,000 is sufficient for training a dependable model. With that record size, the model which is trained and tested at an average of 64.14 and 0.51 seconds achieves the RMSE of 6.97 and $4.61 \mathrm{kWh} / \mathrm{m}^{2}$ for heating and cooling loads, respectively. It should be noted that this testing time relates to the forecasting of 4,500 samples. This figure denotes that the model has the capability of processing 8,8000 building records in one second.

The calculated confidence intervals at that point assure building a reliable model not only because the narrow band but also due to the fact that the data covers the space of possible values of the selected features for building design. Moreover, the use of 10-fold cross-validation and a random selection of records grantees a fair test procedure. Therefore, the upper bound of the RMSE in the presented graph can be considered as models' worst performance.

To show the model performance using the full capacity of generated data, 


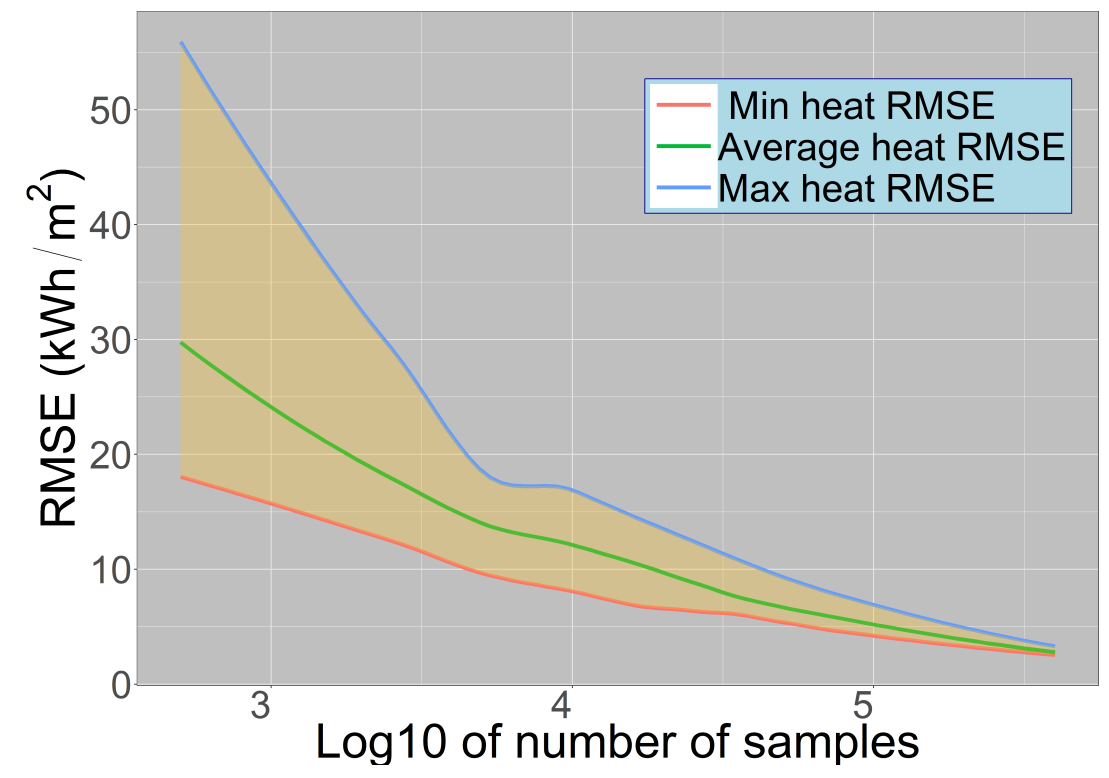

(a)

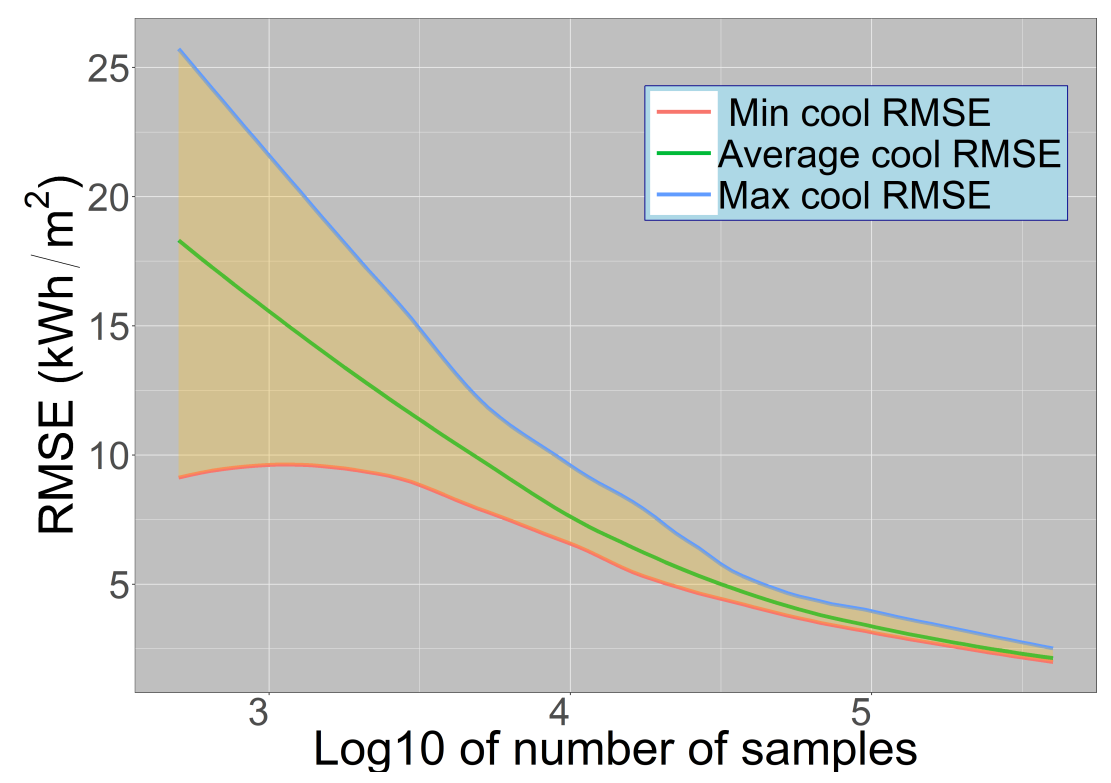

(b)

Figure 7: RMSE of predicting (a) heating and (b) cooling loads by varying the number of total number of samples used for training 


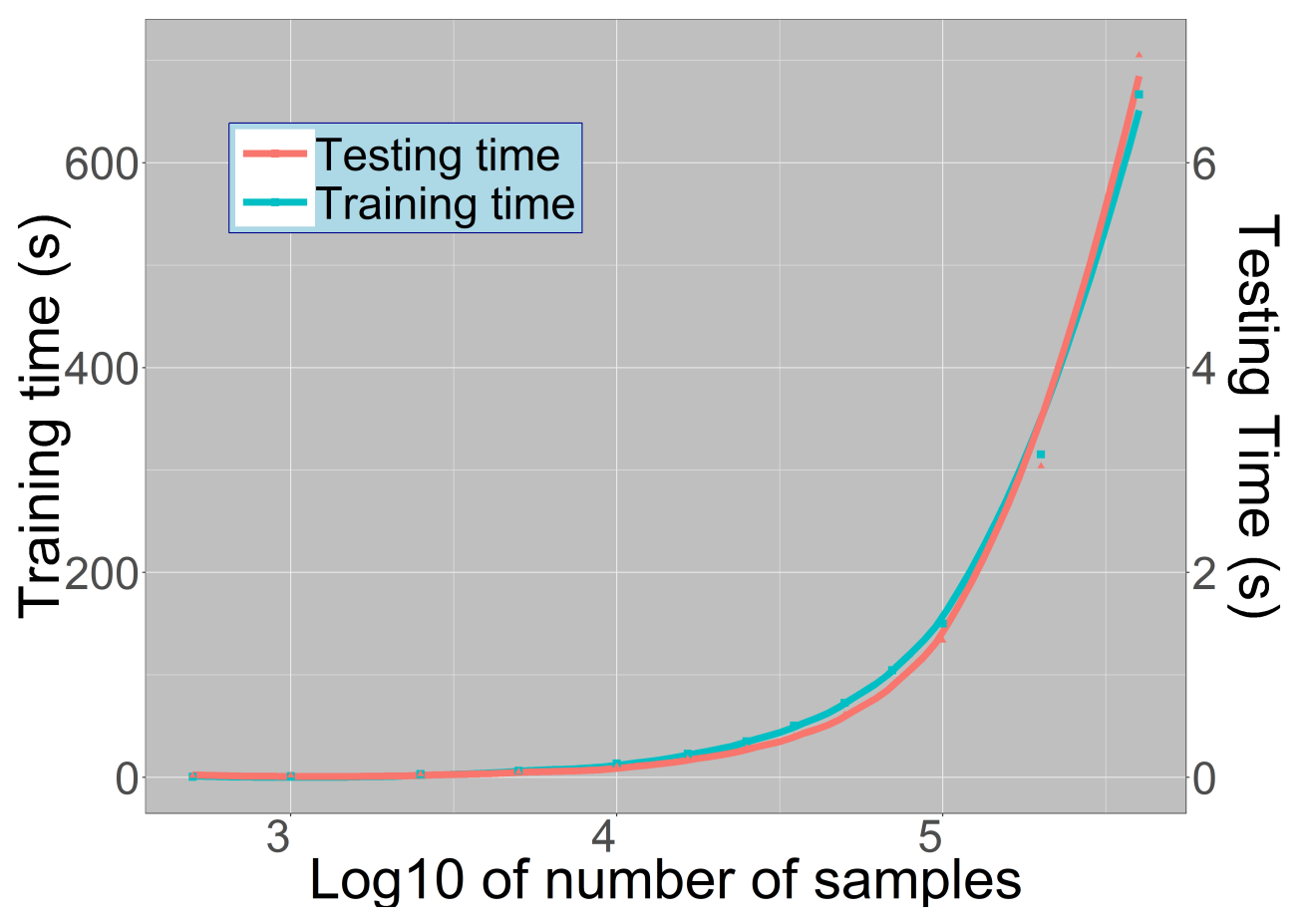

Figure 8: Average training and testing time of energy loads models the versus number of records.

400,000 records are fitted into a model in 6672 seconds achieving the accuracy of 2.78 and $2.12 \mathrm{kWh} / \mathrm{m}^{2}$ for heating and cooling loads (4\% of mean energy load values). Figure 9 shows the predicted (model estimation) vs actual (simulated) values of energy loads testing over 30,000 buildings along with the error distributions.

Due to the nature of RF models in training independent trees in which different feature set is selected, they are able to determine input variables importance in target estimation. This competency which is known as sensitivity analysis provides useful information in the analysis of the studied system. In this study, we fitted $30 \mathrm{RF}$ model over 100,000 random building samples to generate a better empirical distribution of feature importance. Figure 10 illustrated the results of the sensitivity analysis of these RF models, which are configured based on the MOO algorithm outputs (best hyper-parameters set).

In comparison with the results from training two different models for 


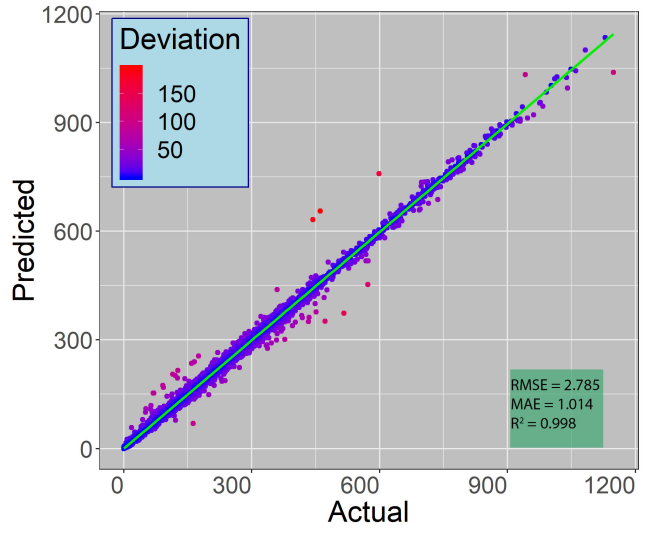

(a)

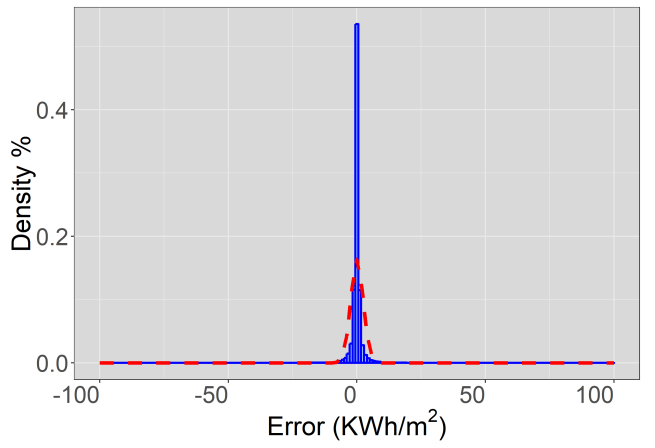

(c)

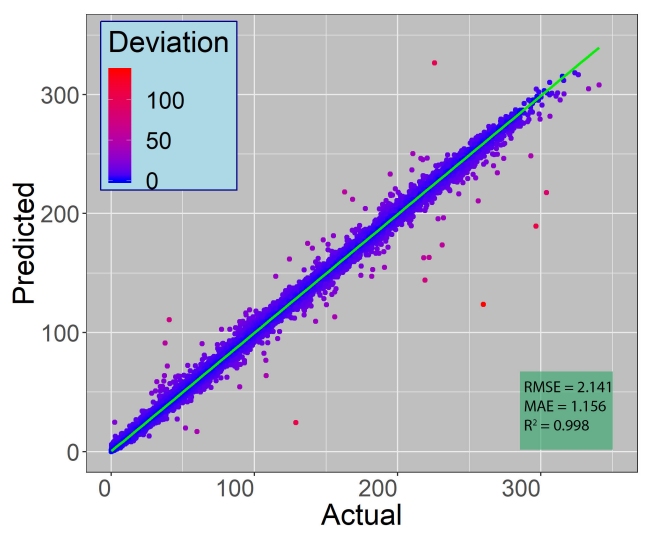

(b)

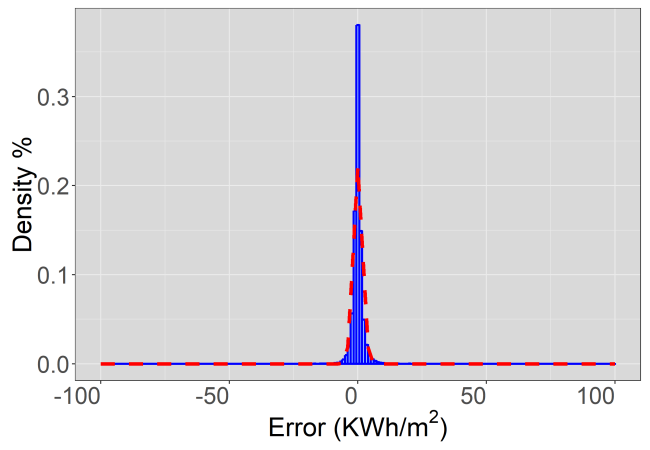

(d)

Figure 9: Actual and predicted (a) heating and (b) cooling and (c) and (d) their error 


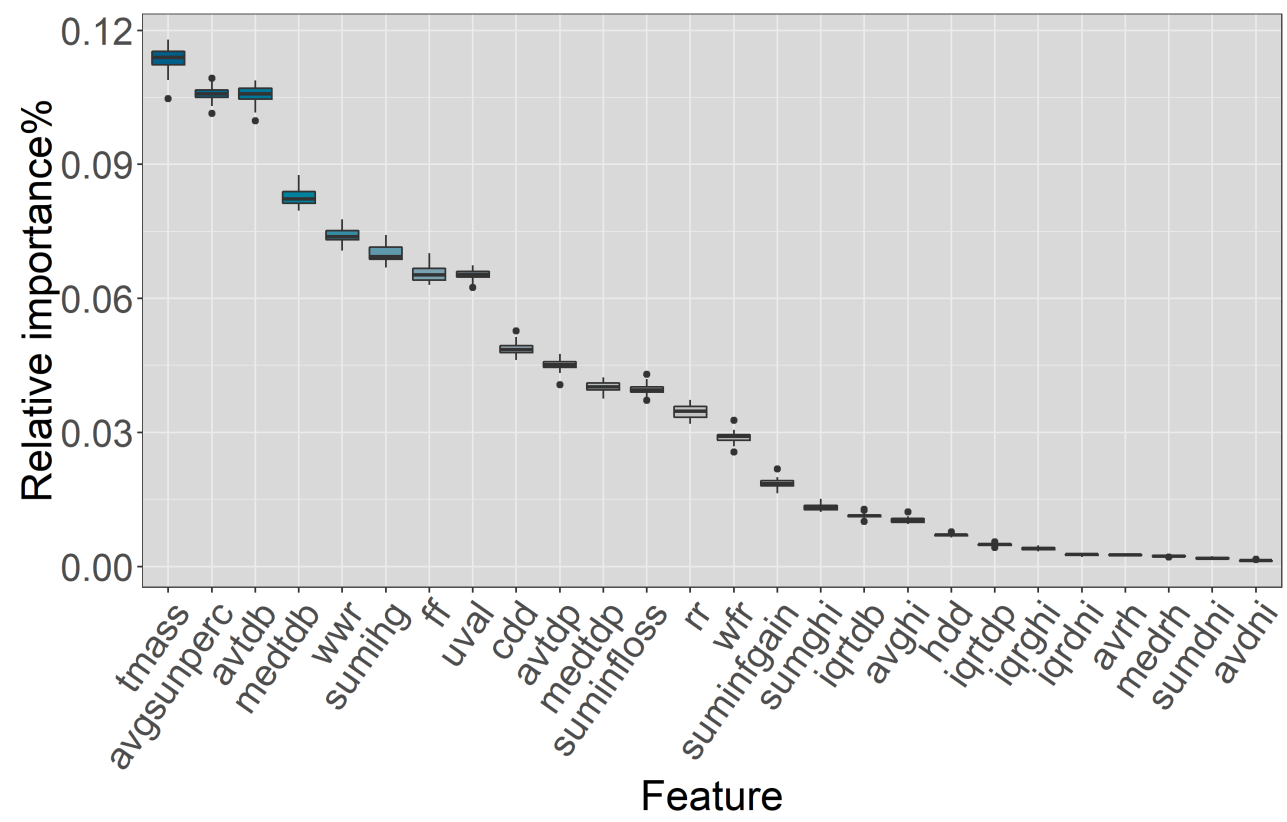

Figure 10: Importance of features for energy loads prediction using RF model.

each of heating and cooling loads [6], it can be seen the important features in our model is a combination of those in two separate models. Moreover, the results indicate that prediction of heating loads mostly rely on building characteristics while cooling load forecasting depends on weather features. Here, the unimportant variables are 'avrh', 'avdni', 'iqrdni', 'iqrghi', 'medrh', 'sumdni', however, 'avghi' and 'sumghi', which had an insignificant impact on modelling cooling loads still play a considerable role in this model. Although the advanced machine learning can ignore unimportant features despite the traditional statistical modelling, removing those from the data can reduce the model time complexity and slightly increase the accuracy. Table 5 presents the results of testing the model by removing the identified features. It can be seen that the RMSE fluctuations of the folds are also reduced compared to the original model.

\section{Conclusion}

This research addresses the issues regarding inaccurate modelling of building energy loads using ML techniques. As mentioned in the reviewed litera- 
Table 5: Performance comparison of ML models including all features and removing unimportant ones.

\begin{tabular}{|c|c|c|c|c|}
\hline \multirow{2}{*}{ Parameters } & \multicolumn{2}{|c|}{ All inputs } & \multicolumn{2}{|c|}{ Selected inputs } \\
\hline & Heating & Cooling & Heating & Cooling \\
\hline $\operatorname{RMSE}\left(k W h / m^{2}\right)$ & $6.97 \pm 3.29$ & $4.61 \pm 2.02$ & $6.19 \pm 1.55$ & $4.48 \pm 1.64$ \\
\hline$\overline{\mathrm{MAE}}\left(\mathrm{kW} h / \mathrm{m}^{2}\right)$ & $2.54^{---}$ & $2 . \overline{3} 6^{-\cdots}$ & $\overline{2} \cdot \overline{4} \overline{4}_{-----}^{-}$ & 2.22 \\
\hline $\bar{R}^{2}-\cdots-\cdots-1$ & $\overline{0.9 \overline{9}} \overline{2}^{-}$ & $0 . \overline{9} \overline{93}-$ & $\overline{0.99} \overline{3}^{--}$ & $\overline{9.993}-$ \\
\hline \multicolumn{5}{|c|}{ Fit time (s) } \\
\hline$\overline{\text { Test }}$ time $(\overline{\mathrm{s}})^{-}$ & $------\overline{0}$ & & & \\
\hline
\end{tabular}

ture, most research studies used MLs without model optimisations, and they proposed to model each energy metric, such as heating and cooling loads separately. The latest attempt to enhance the performance of those data-driven models included exhaustive exploration of variable parameters to choose the best performing model. This paper has proposed a method based on MOO to expedite the process of selecting hyper-parameters, and simultaneously to optimise one single model for forecasting both heating and cooling loads. The main advantages of this method over traditional approaches include a reduction in the time complexity of creating reliable models and improvements in the accuracy of predictions by fine-tuning of the ML models. The proposed approach was evaluated by implementing the random forest decision tree algorithm and testing the accuracy over a building data which was simulated using EnergyPlus. The effectiveness of the proposed approach was demonstrated through comparisons with conventional grid search methods and traditional statistical modelling. Generating an accurate model for calculation of the energy loads with fast and robust process paves the way for more informed and productive design decisions for built environments. Furthermore, the use of ML in the complex buildings goes beyond mere optimisation support matters by offering efficient retrofitting plans, without which it would be a rather cumbersome task for the engineers to carry out complicated calculations readily and make informed decisions.

This study highlights the importance of features in predicting heating and cooling loads using the built-in mechanisms of RF models. The results showed how practically ML models can balance the influential variables on computing energy loads and ignore irrelevant ones without affecting the accu- 
racy. The importance of using ML techniques and model optimisation is more emphasised while complicated energy modelling (e.g. considering occupancy in estimations) using deep learning. By adding layers of learning models to extract complex relations in the data, the number of hyper-parameters and model sensitivity is considerably increased.

The research highlights the potential of ML model-based techniques in modelling building energy indicators, which are sometimes laborious to simulate or calculate using engineering methods. It has been approximated that only three per cent of industrial data is currently being used in a meaningful way. This is why Industry 4.0 has put more emphasis on the utilisation of technologies that could take advantage of the ever-growing data.

As policy tightens on inefficient energy consumption and our understanding of the limitations of BEM-led design decision-making, the necessity for more efficient and flexible models increases. Research over the last few years has been giving greater credence to designing buildings with consideration for medium-term climate change and any number of occupant presence or behaviour uncertainties. Every extension to the potential configurations exponentially inflates the problem space while likely reducing the conventional options solution space. Furthermore, these climate and utilisation properties are internal to BEMs, however, design and retrofit analysis is increasingly considering external and more challenging to integrate properties. The framework shown in this paper demonstrates that algorithmic decision-making capabilities are not nearing their limit and lays a foundation for more complex ML frameworks.

The work presented here makes a significant contribution to research and practice of energy management in buildings. In particular, the prediction of heating and cooling loads, which is mired with several challenges for practitioners, is going to be easier and more accurate using the approach outlined here. The application of ML techniques in the heating and cooling load forecast is not widely used at the moment and the authors claim that this research provides the practitioners with a novel approach to address the challenges they encounter in this important and key area of their routine activities. Although the potentials of ML techniques in predicting heating and cooling loads have been reported by several researchers, the credibility of results may be questionable without the tuning of ML models. Tuning of models not only increases the predictive accuracy, but also reduces model complexity, ease of use, and consistency of predictions. Particularly, when the solution space grows exponentially due to the large number of hyper-parameters, searching 


\section{Acknowledgement}

The research presented in this paper was co-funded by The Data Lab (Edinburgh, UK) and arbnco Ltd (Glasgow, UK), through DataLab SFC Earmarked Grant Agreement: PO DL 00033. This work would also not be feasible without the generous $\mathrm{PhD}$ funding for the first author, which was cofunded by the Engineering The Future scheme from University of University of Strathclyde and the Industry Funded Studentship Agreement with arbnco Ltd (Studentship Agreement Number: S170392-101).

\section{References}

[1] X. Li, C. P. Bowers, T. Schnier, Classification of energy consumption in buildings with outlier detection, IEEE Transactions on Industrial Electronics 57 (11) (2010) 3639-3644. doi :https://doi.org/10.1109/ TIE.2009.2027926.

[2] T. Hong, C. Koo, J. Kim, M. Lee, K. Jeong, A review on sustainable construction management strategies for monitoring, diagnosing, and retrofitting the building's dynamic energy performance: Focused on the operation and maintenance phase, Applied Energy 155 (2015) 671707. doi:http://dx.doi.org/10.1016/j.apenergy.2015.06.043.

[3] T. Nikolaou, D. Kolokotsa, G. Stavrakakis, A. Apostolou, C. Munteanu, Review and State of the Art on Methodologies of Buildings' EnergyEfficiency Classification, in: Managing Indoor Environments and Energy in Buildings with Integrated Intelligent Systems, Springer International Publishing, 2015, Ch. 2, pp. 13-31. doi:https://doi.org/10.1007/ 978-3-319-21798-7. 
[4] H. Kim, A. Stumpf, W. Kim, Analysis of an energy efficient building design through data mining approach, Automation in Construction 20 (1) (2011) 37-43. doi:10.1016/j.autcon.2010.07.006.

[5] S. Seyedzadeh, F. P. Rahimian, I. Glesk, M. Roper, Machine learning for estimation of building energy consumption and performance: a review, Visualization in Engineering 6 (1) (2018) 5. doi:10.1186/ s40327-018-0064-7.

[6] S. Seyedzadeh, F. Pour Rahimian, P. Rastogi, I. Glesk, Tuning machine learning models for prediction of building energy loads, Sustainable Cities and Society 47. doi:10.1016/j.scs.2019.101484.

[7] S. Oliver, S. Seyedzadeh, F. Pour Rahimian, Using real occupancy in retrofit decision-making: reducing the performance gap in low utilisation higher education buildings, in: 36th CIB W78 2019 Conference, 2019.

URL https://strathprints.strath.ac.uk/69619/1/0liver_etal_ CIB2019_Using_real_occupancy_in_retrofit_decision_making. pdf Accessed 28th Jan 2020

[8] M. W. Ahmad, M. Mourshed, Y. Rezgui, Trees vs Neurons: Comparison between random forest and ANN for high-resolution prediction of building energy consumption, Energy and Buildings 147 (2017) 77-89. doi:10.1016/j.enbuild.2017.04.038.

[9] R. K. Jain, K. M. Smith, P. J. Culligan, J. E. Taylor, Forecasting energy consumption of multi-family residential buildings using support vector regression: Investigating the impact of temporal and spatial monitoring granularity on performance accuracy, Applied Energy 123 (2014) 168178. doi:http://dx.doi.org/10.1016/j.apenergy.2014.02.057.

[10] C. Li, Z. Ding, D. Zhao, J. Yi, G. Zhang, Building energy consumption prediction: An extreme deep learning approach, Energies 10 (10) (2017) 1525. doi:10.3390/en10101525.

[11] J. Massana, C. Pous, L. Burgas, J. Melendez, J. Colomer, Short-term load forecasting in a non-residential building contrasting models and attributes, Energy and Buildings 92 (2015) 322-330. doi:10.1016/j. enbuild.2015.02.007. 
[12] S. Papadopoulos, E. Azar, W. L. Woon, C. E. Kontokosta, Evaluation of tree-based ensemble learning algorithms for building energy performance estimation, Journal of Building Performance Simulation 11 (3) (2018) 322-332. doi:10.1080/19401493.2017.1354919.

[13] S. Seyedzadeh, P. Rastogi, F. Pour Rahimian, S. Oliver, I. Glesk, B. Kumar, Multi-Objective Optimisation for Tuning Building Heating and Cooling Loads Forecasting Models, in: 36th CIB W78 2019 Conference, Newcastle, 2019.

URL https://strathprints.strath.ac.uk/69599/1/Seyedzadeh_ etal_CIB2019_Multi_objective_optimisation_for_tuning_ building_heating_and_cooling_loads.pdf Accessed 28th Jan 2020

[14] S. Kalogirou, C. Neocleous, C. Schizas, Building Heating Load Estimation Using Artificial Neural Networks, in: Proceedings of the 17th international conference on Parallel architectures and compilation techniques, Vol. 8, 1997, pp. 1-8.

URL http://www.inive.org/members_area/medias/pdf/Inive/ clima2000/1997/P159.pdf Accessed 28th Jan 2020

[15] S. Kalogirou, M. Bojic, Artificial neural networks for the prediction of the energy consumption of a passive solar building, Energy 25 (5) (2000) 479-491. doi:10.1016/S0360-5442(99)00086-9.

[16] S. Kalogirou, G. Florides, C. Neocleous, C. Schizas, Estimation of daily heating and cooling loads using artificial Neural Networks, in: Proceedings of CLIMA 2000 International Conference, no. September, Cyprus University of Technology, Naples, 2001, pp. 1-11.

URL http://ktisis.cut.ac.cy/bitstream/10488/883/3/ C41-CLIMA2001.pdf Accessed 28th Jan 2020

[17] R. Yokoyama, T. Wakui, R. Satake, Prediction of energy demands using neural network with model identification by global optimization, Energy Conversion and Management 50 (2) (2009) 319-327. doi:10.1016/j. enconman.2008.09.017.

[18] S. M. Hong, G. Paterson, E. Burman, P. Steadman, D. Mumovic, A comparative study of benchmarking approaches for non-domestic buildings: Part 1 - Top-down approach, International Journal of Sustainable 
Built Environment 2 (2) (2014) 119-130. doi:10.1016/j.ijsbe. 2014. 12.001.

URL http://dx.doi.org/10.1016/j.ijsbe.2014.04.001 Accessed 28th Jan 2020

[19] S. Paudel, M. Elmtiri, W. L. Kling, O. L. Corre, B. Lacarrière, Pseudo dynamic transitional modeling of building heating energy demand using artificial neural network, Energy and Buildings 70 (2014) 81-93. doi: http://dx.doi.org/10.1016/j.enbuild.2013.11.051.

[20] C. Deb, L. S. Eang, J. Yang, M. Santamouris, Forecasting diurnal cooling energy load for institutional buildings using Artificial Neural Networks, Energy and Buildings 121 (2016) 284-297. doi:10.1016/j . enbuild.2015.12.050.

[21] R. Mena, F. Rodríguez, M. Castilla, M. R. Arahal, A prediction model based on neural networks for the energy consumption of a bioclimatic building, Energy and Buildings 82 (2014) 142-155. doi:http://dx. doi.org/10.1016/j.enbuild.2014.06.052.

[22] R. Platon, V. R. Dehkordi, J. Martel, Hourly prediction of a building's electricity consumption using case-based reasoning, artificial neural networks and principal component analysis, Energy \& Buildings 92 (2015) 10-18. doi:10.1016/j.enbuild.2015.01.047.

[23] K. Li, C. Hu, G. Liu, W. Xue, Building's electricity consumption prediction using optimized artificial neural networks and principal component analysis, Energy and Buildings 108 (2015) 106-113. doi:http: //dx.doi.org/10.1016/j.enbuild.2015.09.002.

[24] A. H. Neto, F. A. S. Fiorelli, Comparison between detailed model simulation and artificial neural network for forecasting building energy consumption, Energy and Buildings 40 (12) (2008) 2169-2176. doi:https://doi.org/10.1016/j.enbuild.2008.06.013

[25] Ö. A. Dombayci, The prediction of heating energy consumption in a model house by using artificial neural networks in Denizli-Turkey, Advances in Engineering Software 41 (2) (2010) 141-147. doi:https: //doi.org/10.1016/j.advengsoft.2009.09.012. 
[26] A. Kialashaki, J. R. Reisel, Modeling of the energy demand of the residential sector in the United States using regression models and artificial neural networks, Applied Energy 108 (2013) 271-280. doi: $10.1016 / \mathrm{j}$. apenergy.2013.03.034.

[27] M. Yalcintas, U. A. Ozturk, An energy benchmarking model based on artificial neural network method utilizing US Commercial Buildings Energy Consumption Survey (CBECS) database, International Journal of Energy Research 31 (4) (2007) 412-421. arXiv:arXiv:1011.1669v3, doi:https://doi.org/10.1002/er.1232.

[28] M. Yalcintas, An energy benchmarking model based on artificial neural network method with a case example for tropical climates, International Journal of Energy Research 30 (14) (2006) 1158-1174. doi:https:// doi.org/10.1002/er.1212.

[29] S.-M. M. Hong, G. Paterson, D. Mumovic, P. Steadman, Improved benchmarking comparability for energy consumption in schools, Building Research \& Information 42 (1) (2014) 47-61. doi:https://doi. org/10.1080/09613218.2013.814746.

[30] P. De Wilde, The gap between predicted and measured energy performance of buildings: A framework for investigation, Automation in Construction 41 (2014) 40-49. doi:10.1016/j.autcon.2014.02.009.

[31] S. L. Wong, K. K. W. Wan, T. N. T. Lam, Artificial neural networks for energy analysis of office buildings with daylighting, Applied Energy 87 (2) (2010) 551-557. doi:10.1016/j.apenergy.2009.06.028.

[32] F. Ascione, N. Bianco, C. De Stasio, G. M. Mauro, G. P. Vanoli, Artificial neural networks to predict energy performance and retrofit scenarios for any member of a building category: A novel approach, Energy 118 (2017) 999-1017. doi:http://dx.doi.org/10.1016/j.energy. 2016. 10.126 .

[33] B. Dong, C. Cao, S. E. Lee, Applying support vector machines to predict building energy consumption in tropical region, Energy and Buildings 37 (5) (2005) 545-553. doi:https://doi.org/10.1016/j.enbuild. 2004.09.009. 
[34] Q. Li, Q. Meng, J. Cai, H. Yoshino, A. Mochida, Applying support vector machine to predict hourly cooling load in the building, Applied Energy 86 (10) (2009) 2249-2256. doi:10.1016/j.apenergy. 2008.11. 035.

[35] Q. Li, Q. Meng, J. Cai, H. Yoshino, A. Mochida, Predicting hourly cooling load in the building: A comparison of support vector machine and different artificial neural networks, Energy Conversion and Management 50 (1) (2009) 90-96. doi:10.1016/j . enconman.2008.08.033.

[36] Z. Hou, Z. Lian, An application of support vector machines in cooling load prediction, in: 2009 International Workshop on Intelligent Systems and Applications, ISA 2009, Vol. 2, IEEE, 2009, pp. 1-4. doi:10.1109/ IWISA.2009.5072707.

[37] L. X. L. Xuemei, L. J.-h. L. Jin-hu, D. L. D. Lixing, X. G. X. Gang, L. J. L. Jibin, Building Cooling Load Forecasting Model Based on LSSVM, Asia-Pacific Conference on Information Processing 1 (2009) 55-58. doi:10.1109/APCIP.2009.22.

[38] X. P. Zhang, R. Gu, Electrical energy consumption forecasting based on cointegration and a support vector machine in China, in: WSEAS Transactions on Mathematics, Vol. 6, 2007, pp. 818-883. URL http://citeseerx.ist.psu.edu/viewdoc/download?doi=10. 1.1.533.9017\&rep=rep1\&type=pdf Accessed 28th Jan 2020

[39] F. Lai, F. Magoulès, F. Lherminier, Vapnik's learning theory applied to energy consumption forecasts in residential buildings, International Journal of Computer Mathematics 85 (10) (2008) 1563-1588. doi: https://doi.org/10.1080/00207160802033582.

[40] Q. Li, P. Ren, Q. Meng, Prediction model of annual energy consumption of residential buildings, in: 2010 International Conference on Advances in Energy Engineering, ICAEE 2010, IEEE, 2010, pp. 223-226. doi: 10.1109/ICAEE. 2010.5557576.

[41] H.-x. Zhao, F. Magoulès, Parallel Support Vector Machines Applied to the Prediction of Multiple Buildings Energy Consumption, Journal of Algorithms \& Computational Technology 4 (2) (2010) 231-249. doi: 10.1260/1748-3018.4.2.231. 
[42] H. C. Jung, J. S. Kim, H. Heo, Prediction of building energy consumption using an improved real coded genetic algorithm based least squares support vector machine approach, in: Energy and Buildings, Vol. 90, Elsevier B.V., 2015, pp. 76-84. doi:10.1016/j.enbuild.2014.12.029.

[43] Y. Chen, H. Tan, Short-term prediction of electric demand in building sector via hybrid support vector regression, Applied Energy 204 (2017) 1363-1374. doi:https://doi.org/10.1016/j.apenergy. 2017.03.070.

[44] A. Tsanas, A. Xifara, Accurate quantitative estimation of energy performance of residential buildings using statistical machine learning tools, Energy and Buildings 49 (2012) 560-567. doi:10.1016/j.enbuild. 2012.03.003.

[45] S. Papadopoulos, E. Azar, W.-L. Woon, C. E. Kontokosta, Evaluation of tree-based ensemble learning algorithms for building energy performance estimation, Journal of Building Performance Simulation 1493 (2017) 111. doi:https://doi.org/10.1080/19401493.2017.1354919.

[46] H. Deng, D. Fannon, M. J. Eckelman, Predictive modeling for US commercial building energy use: A comparison of existing statistical and machine learning algorithms using CBECS microdata, Energy and Buildings 163 (2018) 34-43. doi:https://doi.org/10.1016/j.enbuild. 2017.12.031.

[47] Z. Wang, Y. Wang, R. Zeng, R. S. Srinivasan, S. Ahrentzen, Random Forest based hourly building energy prediction, Energy and Buildings 171 (2018) 11-25. doi:https://doi.org/10.1016/j.enbuild.2018. 04.008

[48] Z. Li, Y. Han, P. Xu, Methods for benchmarking building energy consumption against its past or intended performance: An overview (2014). doi:https://doi.org/10.1016/j.apenergy.2014.03.020.

[49] F. Khayatian, L. Sarto, G. Dall'O', Application of neural networks for evaluating energy performance certificates of residential buildings, Energy and Buildings 125 (2016) 45-54. doi:10.1016/j.enbuild.2016. 04.067. 
[50] D. Popescu, F. Ungureanu, A. Hernández-Guerrero, Simulation models for the analysis of space heat consumption of buildings, Energy 34 (10) (2009) 1447-1453. doi : https://doi.org/10.1016/j.energy. 2009.05.035.

[51] H.-X. Zhao, F. Magoulès, Feature Selection for Predicting Building Energy Consumption Based on Statistical Learning Method, Journal of Algorithms \& Computational Technology 6 (1) (2012) 59-77. doi:https: //doi.org/10.1260/1748-3018.6.1.59.

[52] S. Singaravel, J. Suykens, P. Geyer, Deep-learning neural-network architectures and methods: Using component-based models in buildingdesign energy prediction, Advanced Engineering Informatics 38 (2018) 81-90. doi:10.1016/j.aei.2018.06.004.

[53] S. Touzani, J. Granderson, S. Fernandes, Gradient boosting machine for modeling the energy consumption of commercial buildings, Energy and Buildings 158 (2018) 1533-1543. doi:10.1016/j.enbuild.2017. 11.039 .

[54] V. F. Rodriguez-Galiano, J. A. Luque-Espinar, M. Chica-Olmo, M. P. Mendes, Feature selection approaches for predictive modelling of groundwater nitrate pollution: An evaluation of filters, embedded and wrapper methods, Science of the Total Environment 624 (2018) 661-672. doi:10.1016/j.scitotenv.2017.12.152.

[55] P. Rastogi, M. Andersen, Embedding Stochasticity in Building Simulation Through Synthetic Weather Files, in: Proceedings of BS, no. EPFL-CONF-208743, IBPSA, 2015. URL http://infoscience.epfl.ch/record/208743 Accessed 28th Jan 2020

[56] K. Deb, Multi-objective optimization, in: Search Methodologies, Springer, Boston, 2013, pp. 403-449. doi:https://doi.org/10.1007/ 978-1-4614-6940-7_15.

[57] P. Rastogi, E. Polytechnique, F. D. Lausanne, Gaussian-Process-Based Emulators for Building Performance Simulation, in: Building Simulation 2017: The 15th International Conference of IBPSA, IBPSA, San Francisco, 2017. 
URL https://infoscience.epfl.ch/record/252858/files/ BS2017_448.pdf Accessed 28th Jan 2020 